\title{
Tradução científica em língua portuguesa: o caso da Origem das espécies de Charles Dar- win $^{1}$
}

\author{
Cristina de Amorim Machado*
}

\section{Introdução}

A circulação do conhecimento científico pode ser estudada de diferentes formas, sendo um tema bastante abrangente, tendo em vista que ninguém negaria que as ciências circulam, e não é de hoje. Esse tema abarca desde os atores mais óbvios, como cientistas, instrumentos, teorias, experimentos e fatos, passando por institutos de pesquisa, universidades, agências de fomento, escolas, livros, editoras e periódicos científicos e de divulgação, até chegar a livros e filmes de ficção, séries, quadrinhos e músicas. Isso revela que a circulação das ciências pode ser entendida em várias instâncias, que tenho tratado como produção/recepção, divulgação e educação. Talvez ainda seja o caso de perguntar o que é isso que circula, tendo em vista sua multiplicidade de formas, mas não é nessa discussão que me deterei, muito embora acredite que haja aqui uma contribuição para tal.

O que me interessa neste artigo é a literatura científica, que também é um conceito amplo: artigos e livros técnico-científicos (produção/recepção);

\footnotetext{
${ }^{1}$ Os primeiros resultados desta pesquisa, iniciada há cinco anos, foram apresentados no Congresso da Abrapt realizado em Uberlândia em 2016.O título original da primeira edição do livro, de 1859, é On the origin of species by means of natural selection, e o título definitivo da sexta e última edição, de 1876, The origin of species by means of natural selection. Contudo, é mais usual encontrarmos na literatura especializada a forma abreviada, Origin of species, ou simplesmente Origin. Em português, as edições reduzem o título para A origem das espécies ou Origem das espécies. Nos campos da Biologia, da Filosofia e História da Biologia, e dos Science Studies, no entanto, costuma-se mencionar a obra magna de Darwin, em geral, como a Origem, independentemente de se estar considerando como livro ou obra, e independentemente de a edição citada ser original ou traduzida. É assim que esse livro-obra será aqui chamado.

* Universidade Estadual de Maringá (UEM).
} 
jornais, revistas, blogs e livros de divulgação científica (divulgação); manuais, apostilas e livros didáticos (educação). Mais especificamente, vou tratar aqui do livro científico traduzido, no caso, Origem das espécies, de Charles Darwin (1809-1882), cuja primeira edição original foi publicada em 1859, e cuja primeira tradução integral em língua portuguesa só saiu em 1913, no Porto, pela Livraria Chardron, de Lelo \& Irmão, a partir das mãos do médico Joaquim Dá Mesquita Paúl (DARWIN, 2009b).

A tradução é importante no campo das ciências porque internacionaliza a literatura científica da língua de partida e forma uma cultura científica na língua de chegada. O caso da coleção Os Pensadores no Brasil dos anos 1970 é um exemplo disso, reconstruindo entre nós toda uma área de conhecimento, a Filosofia. No entanto isso costuma passar despercebido, tendo em vista a condição de marginalidade da tradução, normalmente invisível, tomada como neutra, um sucedâneo do original, algo mecânico e sem nenhuma interferência dos valores do tradutor. Não é muito comum mencionar-se o tradutor nas referências bibliográficas, por exemplo. Essa dinâmica de invisibilidade só é quebrada nos casos de infidelidade pública (tradutortraidor), quando o tradutor é jogado aos leões por conta de escolhas ou estratégias tradutórias consideradas impróprias. Nesses casos, sempre valeria a pena avaliar se não se trata de desapropriações ou reapropriações, afinal, a escrita tradutora implica uma autoria, ainda que isso, em geral, seja considerado um escândalo (VENUTI, 2002).

Por outro lado, a tradução não é evidentemente a única maneira de formar uma cultura científica, afinal, é possível ler os textos originais. Um exemplo disso são as palavras de Pedro Fonseca (2015, p. 109) sobre a recepção do darwinismo em Portugal: "A ausência prolongada de traduções portuguesas de trabalhos da autoria de Darwin não constituiu um obstáculo ao contacto do público português com os trabalhos e as ideias do naturalista inglês." Ou seja, a recepção de uma teoria, como a da evolução por seleção natural apresentada na Origem, costuma anteceder a tradução da literatura especializada, preparando as condições de demanda dessa tradução. O problema é que a ausência dela pode reforçar a atribuição de valores ao texto de acordo com a "moda" da época. No caso do darwinismo, sobretudo questões positivistas e spencerianas, como veremos brevemente na próxima seção. 
Durante a vida de Darwin houve muito mal-entendido sobre a Origem, incluindo questões tradutórias, que ele tentava dar conta nas edições seguintes, em outras publicações e, sobretudo, na sua farta correspondência. Essas controvérsias constituem a minha primeira premissa. Ela se desdobra, como foi afirmado anteriormente, na recepção do darwinismo no Brasil e em Portugal, claramente temperada com outros elementos (DOMINGUES et al, 2003; PEREIRA, 2001), o que reflete no material didático (BELLINI, 2006; BIZZO, 1991) e, consequentemente, em toda a formação de uma comunidade científica que não está acostumada a ler a bibliografia primária (OLIVEIRA, 2015; FERREIRA \& MACHADO, 2018; PETRUCCI \& BELLINI, 2018). Ou seja, a Origem é pouco lida. No Brasil, quando acontece a raridade de ser lida, normalmente é lida em português. Então a minha problematização geral tem girado em torno do seguinte: Que traduções temos disponíveis? De que edições originais? Quem são os tradutores e quais são seus contextos? Há diferenças relevantes entre as traduções? Se sim, em que isso afeta a circulação do conhecimento científico dentro e fora dos limites acadêmicos? Decerto não pretendo dar conta de tudo isso neste artigo, mas essas questões compõem o meu fio condutor.

Postulo aqui que a tradução da literatura científica tem papel determinante na circulação do conhecimento "dentro e fora" do circuito acadêmico, que entendo, junto com Bruno Latour (2011), como uma rede de atores humanos e não humanos (animais, instrumentos, teorias, fatos, livros, artigos, etc.) que interagem e que, portanto, não contempla essa noção de dentro (racional, objetivo) e fora (irracional, subjetivo). A noção de tecnociência (ciência, tecnologia e sociedade), proposta por Latour, abarca as ideias de rede híbrida, de que o fato científico é construído coletivamente e de que ciência e política não se excluem, sendo tratadas nos mesmos termos, o que não significa que suas redes tenham os mesmos elementos. O próprio livro científico é um exemplo disso, tendo em vista a escolha de citações/autores citados e as estratégias retóricas de construção do fato científico. Latour analisa essa questão no primeiro capítulo de seu livro Ciência em ação, que trata justamente da literatura científica (ibid, p. 45-65). ${ }^{2}$

\footnotetext{
${ }^{2}$ Para ver um estudo das citações que Darwin faz na Origem à luz das ideias de Latour, cf. Navarro, 2018.
} 
Ademais, no caso da Origem, os problemas com a sua recepção já começam no próprio século XIX e aparecem nas primeiras traduções em alemão e francês, passam pelo XX e se arrastam até o XXI. Isso decerto afeta a formação científica e a circulação do conhecimento, como muito bem destacou Fonseca (2015), que reservou à tradução cinco seções de sua tese sobre o darwinismo em Portugal $^{3}$ e ainda mapeou o que falta ser feito: "Aprofundarse a análise das traduções dos seus trabalhos para a Língua Portuguesa, através do estudo do perfil dos seus tradutores e da identificação das edições das quais foram traduzidas [...]" (FONSECA, 2015, p. 579). Espero que o presente artigo seja um primeiro passo para preencher essa lacuna. Tendo isso em vista, postulo também que algumas chaves de leitura no campo dos Science Studies, especialmente nos estudos de controvérsias, só se revelam com um olhar mais cuidadoso para a tradução, tendo em vista que muitas delas passam pelo problema da nomenclatura e de seus usos nos vários contextos linguísticos.

Diante desse quadro, meu objetivo geral de pesquisa tem sido analisar o papel da tradução na circulação do conhecimento sobre a Origem e na recepção do darwinismo no Brasil e em Portugal. No entanto, neste artigo, por uma questão de espaço, me restrinjo aos seguintes objetivos específicos: 1) apresentar um levantamento das traduções em português da Origem; 2) tirar da invisibilidade pelo menos os nomes dos tradutores envolvidos nessa história, deixando para outro trabalho um relato mais detalhado sobre isso; e 3) apresentar alguns trechos da problemática versão da Editora Escala, traduzida por André Campos Mesquita (DARWIN, 2009c).

Para dar conta dessa tarefa geral, fiz uma análise da bibliografia primária e da bibliografia secundária sobre a Origem, sua história e suas traduções no Brasil e em Portugal. Fiz também entrevistas com tradutores e outros personagens dessa história. Além disso, participei de uma leitura coletiva da Origem ao longo de dois anos e meio, que fez parte das atividades regulares

\footnotetext{
${ }^{3}$ As seções são as seguintes: 1) Na introdução, "2.2 As traduções portuguesas de trabalhos de Darwin"; 2) Na parte 1, "1.4 O tradutor é um divulgador"; 3) Na parte 2, "4.6 A tradução e a recensão no acompanhamento dos estudos evolutivos"; 4) No anexo II, "Traduções de trabalhos de Charles Darwin"; e 5) No anexo IV, "Série de imagens 3 - traduções portuguesas de trabalhos de Darwin".
} 
do GP de Science Studies da UEM, grupo de pesquisa que coordeno na Universidade Estadual de Maringá.

Esta pesquisa, que se iniciou há cinco anos, tem contribuído para revelar a realidade da tradução na área das ciências e torná-la visível para um público que costuma tomá-la como garantia da palavra do autor. Ademais, tem servido de base para um melhor entendimento de certos conceitos darwinistas ou atribuídos a Darwin, ainda que equivocadamente, como o conceito de progresso. É importante também para mostrar os perigos de uma tradução irresponsável para a formação científica - que já tem seus próprios problemas, como o tecnicismo, a fragmentação, o produtivismo e a especialização excessiva; e para alertar sobre as repercussões disso na recepção (já problemática) do darwinismo no Brasil e em Portugal.

Neste artigo, começarei falando brevemente da obra e seu histórico de edições e traduções. Na sequência, apresentarei uma cronologia da Origem em português e, depois, o caso problemático da tradução publicada pela Editora Escala em 2009.

\section{Visão geral da Origem: edições e traduções}

Em 1859, o naturalista britânico Charles Darwin publicou a sua principal obra, e uma das mais notáveis da história das ciências, a Origem das espécies. Nesse livro - que, como veremos aqui, são muitos - são tecidos os primeiros fios da Biologia moderna, na época ainda chamada de História Natural. É nele que Darwin publica pela primeira vez a sua ideia - já formulada anos antes - de que todas as espécies descendem de um ancestral comum e não são fixas - como se acreditava até então -, mas evoluem por seleção natural. É o que ele chama de "theory of descent with modification through variation and natural selection" (DARWIN, 1876, p. 404), traduzido assim por Ana Afonso (DARWIN, 2009a, p. 397): “teoria da descendência com modificações através da variação e da selecção natural". Isso quer dizer que, ao longo de muito tempo e por conta das mais diferentes circunstâncias, as espécies variam, se modificam. Essa variação pode ou não ser favorável para a espécie, o que vai definir se ela se adapta ou não às mudanças e, consequentemente, se ela sobrevive, se reproduz e passa adiante a variação, ou não. Nesse úl- 
timo caso temos a extinção da espécie e, no primeiro, a seleção e a descendência com modificação. Nos 17 anos que se seguiram, a Origem teve mais cinco edições (1860, 1861, 1866, 1869, 1872-1876) revistas por Darwin e editadas por John Murray.

Além de revolucionário, esse livro - com seus vários textos - tem uma história que nos informa deveras sobre o seu conteúdo, daí a importância de revisitá-la, construindo as relações com o seu contexto de escrita e posteriores reescritas tradutórias ou não. Uma questão que marca a sua recepção no Brasil e em Portugal é a deriva indesejada das suas ideias para a sociobiologia ou o que viria a se chamar darwinismo social, cujo pai é o filósofo inglês, Herbert Spencer (1820-1903), e que tem sua fundamentação na ideia de progresso, perfeição, e de que há algumas raças superiores a outras.

A ideia de progresso é rejeitada por Darwin numa seção inteira dedicada a esse tema no capítulo 4 da Origem, que trata da seleção natural. Nesta passagem, isso fica bem claro: "[...] natural selection [...] does not necessarily include progressive development [...]" (DARWIN, 1876, p. 98); assim traduzida por Carlos e Anna Duarte: "[...] a seleção natural [...] não inclui necessariamente o desenvolvimento progressivo [...]" (DARWIN, 2014a, p. 171).

Ele também não concordava com a interpretação social da sua teoria, mas não pôde fazer nada para evitar, afinal, depois de publicadas, palavras e ideias não mais pertencem a seus autores. Suas ideias foram tomadas por Spencer, Francis Galton (1822-1911), entre outros, que as usaram para seus próprios fins, e o desfecho derradeiro disso são produtos como as teorias raciais e outras mazelas afins. Ou seja, o nome de Darwin acabou sendo associado a uma linha de pensamento da qual ele não foi autor, o que vai repercutir na sua recepção no Brasil e em Portugal. Aparentemente, este não foi um fenômeno exclusivamente luso-brasileiro, mas não se pode negar que a recepção enviesada instrumentalizou o higienismo, o racismo e a eugenia entre nós (DOMINGUES et al, 2003; PEREIRA, 2001).

Essa mescla do darwinismo com as ideias de progresso encontra raízes não só em Spencer, mas também em Jean-Baptiste Lamarck (1744-1829). Tanto Darwin quanto Lamarck explicavam que as espécies não eram fixas, ambos compartilhavam a ideia de que os seres vivos mudam, mas, para Dar- 
win, ao contrário de Lamarck, a evolução não era resultado de uma tendência dos seres vivos a progredirem. Numa carta a seu amigo botânico Joseph Hooker (1817-1911), isso também ficou registrado: “Heaven forfend me from Lamarck nonsense of a 'tendency to progression'" [Deus me proteja do absurdo lamarckista de uma "tendência ao progesso"] (DARWIN, 1844). Não vou me ater a mais detalhes para não fugir do assunto tratado aqui, apenas mais um sobre o termo "evolução". Muitos livros costumam dizer que o termo evolução foi cunhado por Darwin e Lamarck, o que não é verdade. Como diz Bellini (2006, p. 20): “Lamarck utilizou o termo transformismo e Darwin usou o termo descendência por modificação". Além disso, já se falava em "evolução" bem antes deles, mas, talvez por conta da relação muito em voga no positivista século XIX entre os termos "evolução" e "progresso", na primeira edição da Origem Darwin sequer usa o termo evolution. A única ocorrência, na forma de verbo, é justamente na última linha do livro, talvez a mais famosa de todas, "[...] from so simple a beginning endless forms most beautiful and most wonderful have been, and are being, evolved." (DARWIN, 1859, p. 490), traduzida assim por Eugênio Amado: “as formas mais belas, mais maravilhosas, evoluíram a partir de um início tão simples, e ainda prosseguem hoje em dia neste desenvolvimento." (DARWIN, 2002, p. 381).

Além da Origem, Darwin publicou outros textos e livros nos quais desdobrou ainda mais a sua teoria, e escreveu uma série de outros documentos não publicados por ele, como cartas e cadernos de notas, mas que são fontes valiosas para a história das ciências. Todas essas fontes documentais e bibliográficas encontram-se nos arquivos dos sites Darwin Online e Darwin Correspondence Project. Foi lá que encontrei informações iniciais sobre as primeiras traduções, que têm a seguinte cronologia (importante lembrar que novas traduções foram feitas para esses idiomas e de edições originais diferentes).
Alemão - 1860
Holandês - 1860-1
Francês - 1862
Russo - 1864 


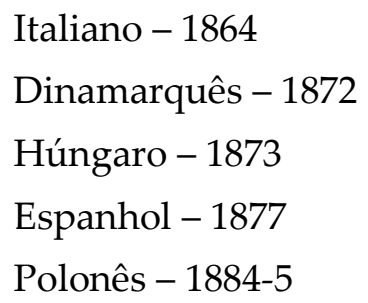

Em relação às traduções para o português, o arquivo Darwin Online é muito enxuto, só apresenta informações sobre a tradução de 2009 de Ana Afonso (DARWIN, 2009a), ignorando toda uma história que remete a, pelo menos, 100 anos antes. A igualmente enxuta literatura sobre o assunto (FREEMAN, 1977; FONSECA, 2015) oferece um pouco mais de informações, mas ainda assim é incipiente. Mais detalhes dessa história, colhidos em documentos, paratextos das edições da Origem e entrevistas feitas no Brasil e em Portugal, serão apresentados em outro trabalho por uma questão de espaço, mas a cronologia com algumas informações e as capas são apresentadas a seguir.

\section{Cronologia e capas da Origem em português ${ }^{4}$}

\begin{tabular}{|c|c|c|c|c|}
\hline $\begin{array}{l}\text { Tradutor(a) e } \\
\text { nacionalidade }\end{array}$ & Cidade & Editora & Ano & Observações \\
\hline $\begin{array}{l}\text { Joaquim Dá } \\
\text { Mesquita Paúl } \\
(\mathrm{PT})\end{array}$ & Porto & $\begin{array}{l}\text { Livraria } \\
\text { Chardron, } \\
\text { depois Lello } \\
\text { \& Irmão Edi- } \\
\text { tores, agora } \\
\text { Lello Edito- } \\
\text { res }\end{array}$ & $\begin{array}{l}1913 \\
- \\
2009\end{array}$ & $\begin{array}{l}\text { 6ª edição; tradutor-médico; tradução } \\
\text { do francês de Edmond Barbier (1876); } \\
\text { várias edições, sendo a última revi- } \\
\text { sada por João Arrepia - Figura } 1\end{array}$ \\
\hline $\begin{array}{l}\text { Eduardo Fon- } \\
\text { seca (pretenso) }\end{array}$ & $\begin{array}{l}\text { São } \\
\text { Paulo }\end{array}$ & $\begin{array}{l}\text { Hemus } \\
\text { Ediouro } \\
\text { Folha }\end{array}$ & $\begin{array}{l}1974 \\
- \\
2010\end{array}$ & $\begin{array}{l}\text { Várias reedições; licenciada pela } \\
\text { Ediouro em } 1987 \text { com várias edições } \\
\text { desde então; licenciada em } 2010 \text { pela } \\
\text { Folha, saiu na coleção Livros que Mu- } \\
\text { daram o Mundo; plágio de Joaquim } \\
\text { Paúl - Figura } 10\end{array}$ \\
\hline
\end{tabular}

\footnotetext{
4 Encontrei livros, artigos e outros documentos com traduções parciais e adaptações da Origem que remetem a 1877; no entanto, aqui me aterei às traduções integrais da obra, informando a edição que serviu de original. Por isso também não farei referência à tradução brasileira do esboço da Origem, escrito por Darwin em 1842.
} 


\begin{tabular}{|c|c|c|c|c|}
\hline $\begin{array}{l}\text { Eugênio } \\
\text { Amado (BR) }\end{array}$ & $\begin{array}{l}\text { São } \\
\text { Paulo } \\
\text { Belo } \\
\text { Hori- } \\
\text { zonte }\end{array}$ & $\begin{array}{l}\text { Itatiaia/ } \\
\text { EdUSP, de- } \\
\text { pois Villa } \\
\text { Rica/ Itatiaia, } \\
\text { depois Itati- } \\
\text { aia }\end{array}$ & $\begin{array}{l}1985 \\
- \\
2012\end{array}$ & $\begin{array}{l}1^{a} \text { edição; várias reedições. Esta é a } \\
\text { primeira tradução integral da Origem } \\
\text { em língua portuguesa feita direta- } \\
\text { mente do inglês - Figura } 2\end{array}$ \\
\hline $\begin{array}{l}\text { John Green } \\
\text { (pretenso) }\end{array}$ & $\begin{array}{l}\text { São } \\
\text { Paulo }\end{array}$ & Martin Claret & 2001 & $\begin{array}{l}\text { Várias reedições desde então; plágio } \\
\text { de Joaquim Paúl e Eugênio Amado - } \\
\text { Figura } 11\end{array}$ \\
\hline $\begin{array}{l}\text { Caroline Furu- } \\
\text { kawa (pre- } \\
\text { tensa) }\end{array}$ & $\begin{array}{l}\text { São } \\
\text { Paulo }\end{array}$ & Madras & 2004 & $\begin{array}{l}\text { Várias reedições até 2010; plágio de } \\
\text { Joaquim Paúl; atribuição indevida de } \\
\text { tradução à funcionária da editora - } \\
\text { Figura } 12\end{array}$ \\
\hline $\begin{array}{l}\text { Dora Batista } \\
(\mathrm{PT})\end{array}$ & Lisboa & $\begin{array}{l}\text { Europa Amé- } \\
\text { rica }\end{array}$ & 2005 & $\begin{array}{l}\text { 1ª edição - Tradutora-bióloga - Fi- } \\
\text { gura } 3\end{array}$ \\
\hline $\begin{array}{l}\text { André Cam- } \\
\text { pos Mesquita }\end{array}$ & $\begin{array}{l}\text { São } \\
\text { Paulo }\end{array}$ & $\begin{array}{l}\text { Escala } \\
\text { Lafonte }\end{array}$ & $\begin{array}{l}2005 \\
- \\
2018\end{array}$ & $\begin{array}{l}\text { 6a } \text {. edição; a versão de } 2009 \text { foi publi- } \\
\text { cada sem autorização do tradutor, } \\
\text { tem problemas graves e há indícios } \\
\text { de plágio da tradução espanhola de } \\
1921 \text { - Figura } 13\end{array}$ \\
\hline Ana Afonso & $\begin{array}{l}\text { Leça da } \\
\text { Pal- } \\
\text { meira }\end{array}$ & Planeta Vivo & 2009 & 6⿳a edição; editor-biólogo - Figura 4 \\
\hline $\begin{array}{l}\text { Vitor Guer- } \\
\text { reiro }\end{array}$ & Lisboa & $\begin{array}{l}\text { Guimarães- } \\
\text { Verbo-Babel }\end{array}$ & $\begin{array}{l}2009 \\
2011\end{array}$ & $\begin{array}{l}1^{\text {a }} \text { edição; tradutor-filósofo; introdu- } \\
\text { ção de Michael Ruse - Figura } 5\end{array}$ \\
\hline $\begin{array}{l}\text { Soraya de Frei- } \\
\text { tas }\end{array}$ & $\begin{array}{l}\text { São } \\
\text { Paulo }\end{array}$ & Madras & 2011 & $6^{\text {a }}$ edição - Figura 6 \\
\hline $\begin{array}{l}\text { Carlos/Anna } \\
\text { Duarte }\end{array}$ & $\begin{array}{l}\text { São } \\
\text { Paulo }\end{array}$ & Martin Claret & 2014 & $\begin{array}{l}6^{a} \text {. edição, prefácio de Nélio Bizzo - } \\
\text { Figura } 7\end{array}$ \\
\hline $\begin{array}{l}\text { Daniel Mi- } \\
\text { randa }\end{array}$ & $\begin{array}{l}\text { São } \\
\text { Paulo }\end{array}$ & Edipro & 2018 & $\begin{array}{l}1^{\text {a }} \text { edição, prefácio, revisão e notas de } \\
\text { Nélio Bizzo - Figura } 8\end{array}$ \\
\hline
\end{tabular}




\begin{tabular}{|l|l|l|l|l|}
\hline $\begin{array}{l}\text { Pedro Paulo } \\
\text { Pimenta }\end{array}$ & $\begin{array}{l}\text { São } \\
\text { Paulo }\end{array}$ & Ubu & 2018 & $1^{\text {ạ } \text { edição; tradutor-filósofo - Figura 9 }}$ \\
\hline Ricardo Santos & Lisboa & $\begin{array}{l}\text { Relógio } \\
\mathrm{d}^{\prime} \text { água }\end{array}$ & $\begin{array}{l}6^{\underline{a}} \text {. edição (No prelo); tradutor-bió- } \\
\text { logo }\end{array}$ \\
\hline Felipe Costa & Viçosa & $\begin{array}{l}\text { Edição do au- } \\
\text { tor }\end{array}$ & $\begin{array}{l}1^{\underline{a}} \text { edição (Em andamento); tradutor- } \\
\text { biólogo }\end{array}$ \\
\hline
\end{tabular}

Fonte: A autora
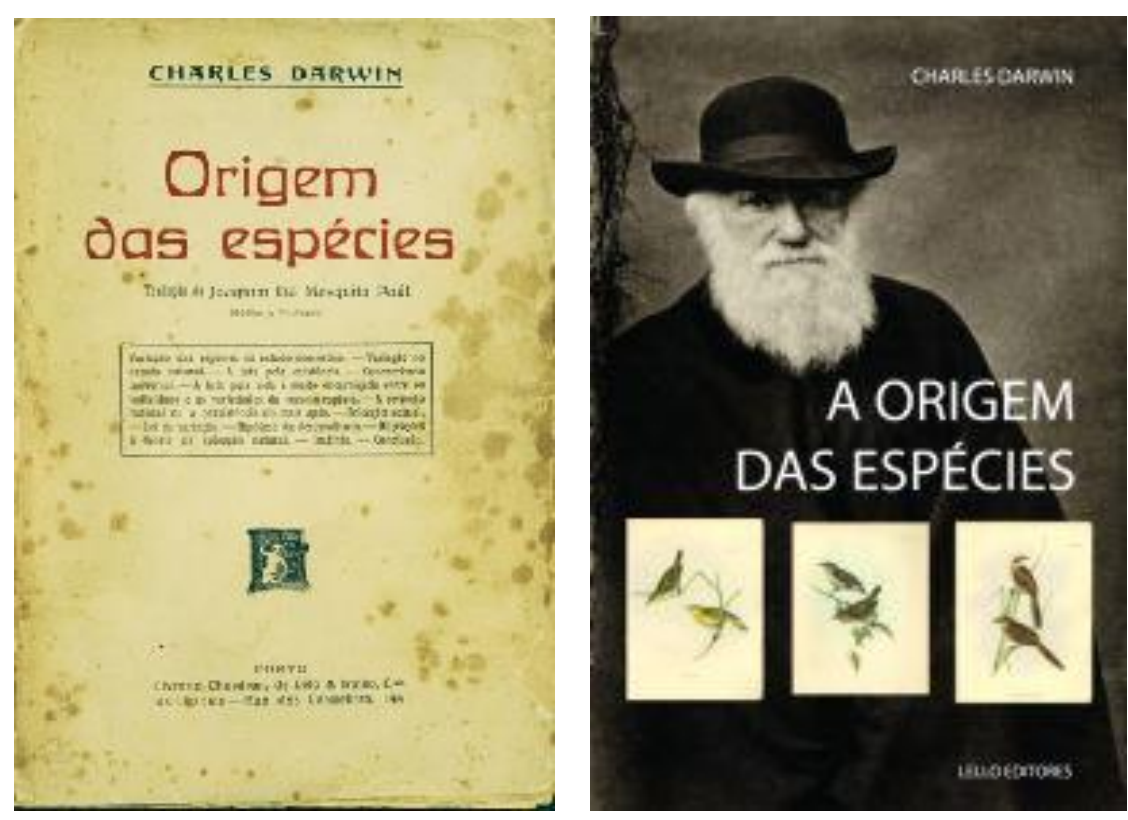

Figura 1 - Capas da tradução de Joaquim Paúl

Fonte: Darwin $(1913 ; 2009 b)$ 


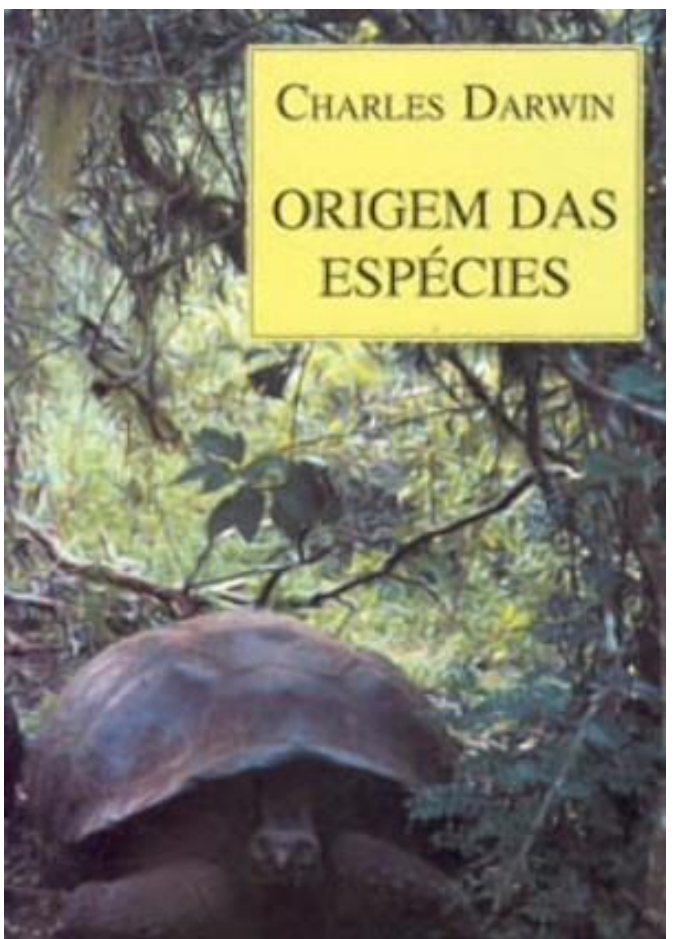

Figura 2 - Capa da tradução de Eugênio Amado Fonte: Darwin (2002)

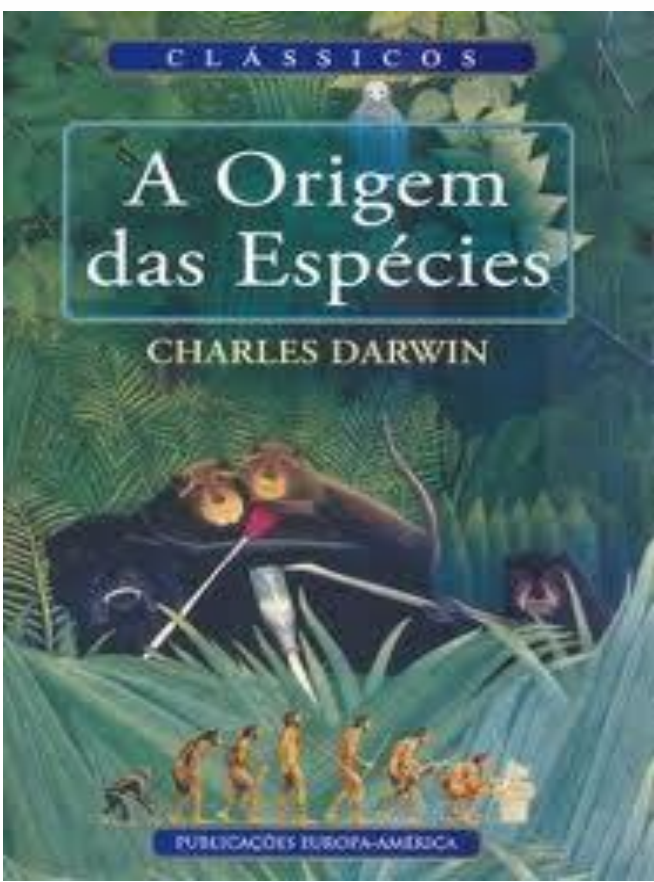

Figura 3 - Capa da tradução de Dora Batista Fonte: Darwin (2005) 


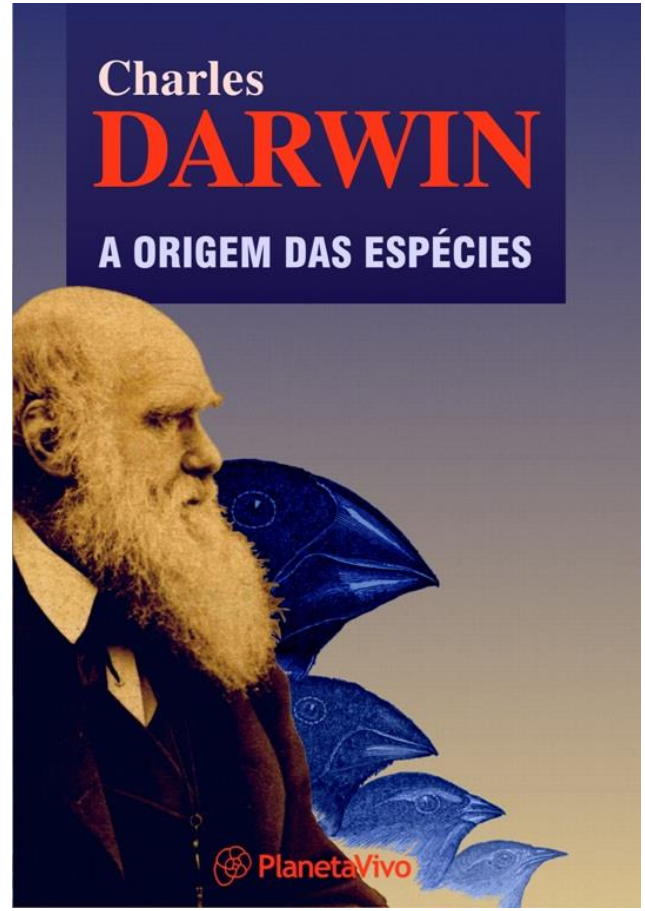

Figura 4 - Capa da tradução de Ana Afonso Fonte: Darwin (2009a)

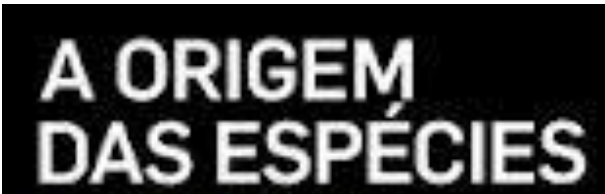

CHARLES DARWIN

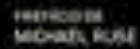

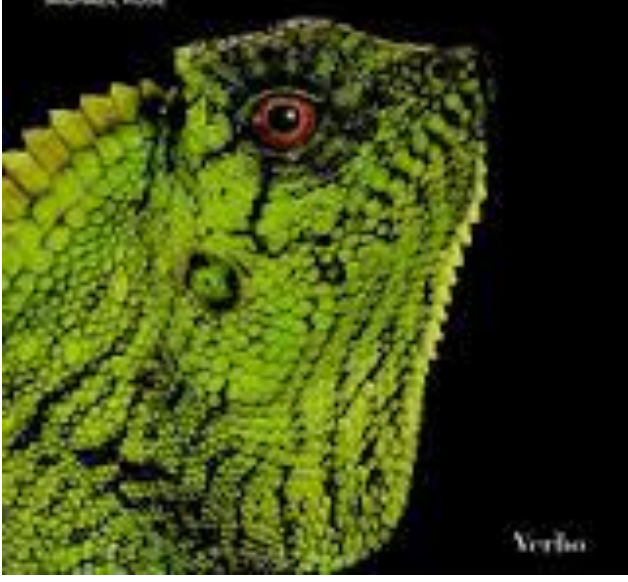

Figura 5 - Capa da tradução de Vitor Guerreiro Fonte: Darwin (2011) 


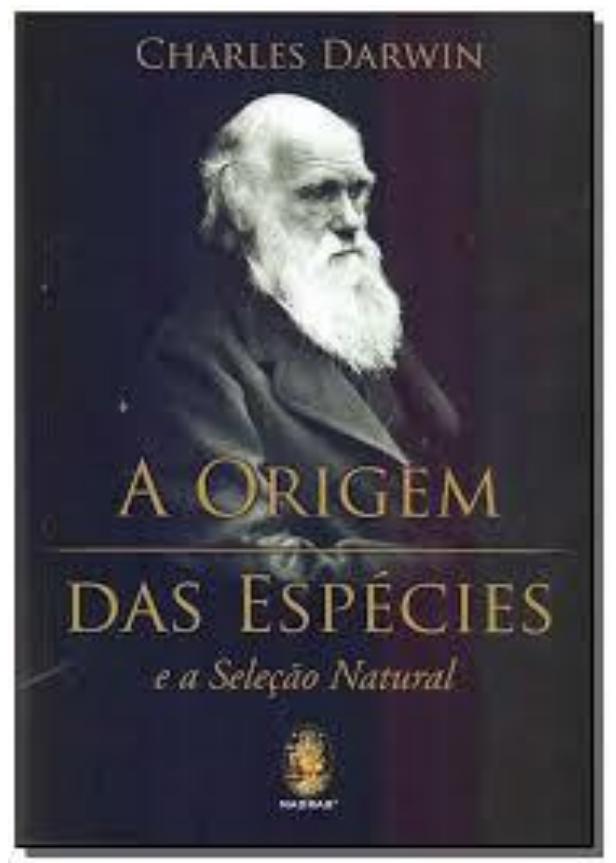

Figura 6 - Capa da tradução de Soraya Freitas Fonte: Darwin (2011)

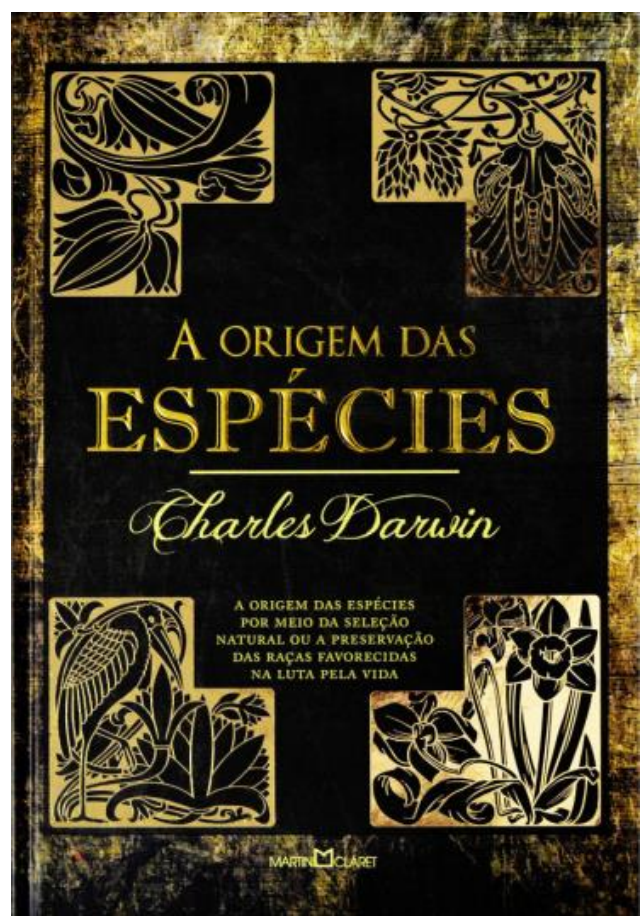

Figura 7 - Capa da tradução de Carlos e Anna Duarte Fonte: Darwin (2014a) 


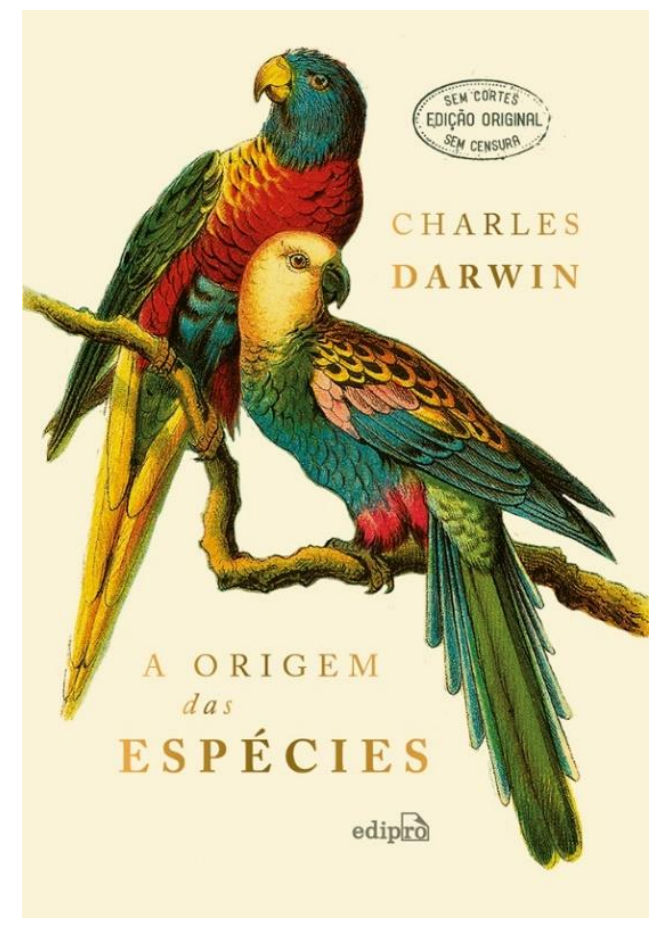

Figura 8 -Capa da tradução de Daniel Miranda Fonte: Darwin (2018b)

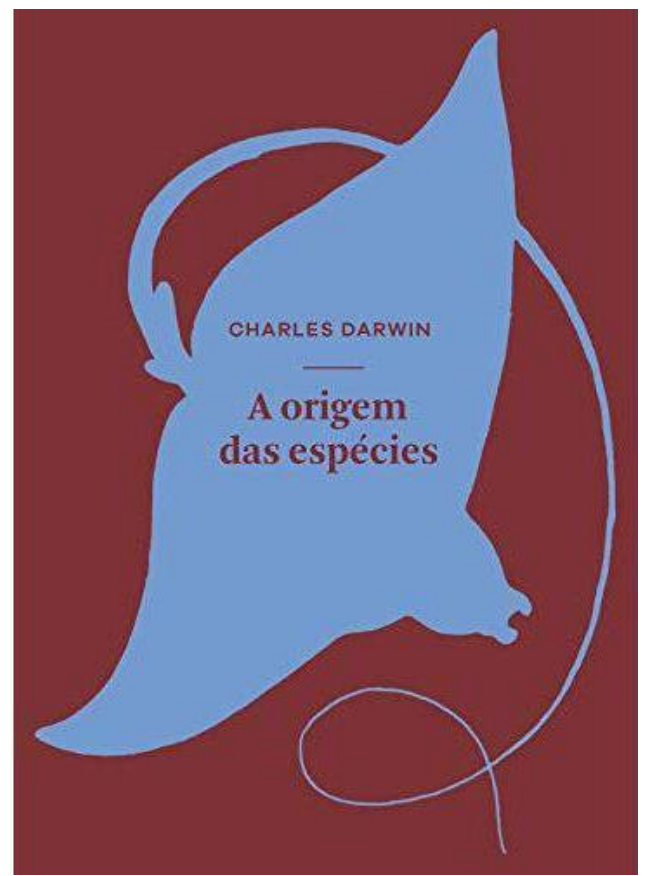

Figura 9 - Capa da tradução de Pedro Pimenta Fonte: Darwin (2018a) 


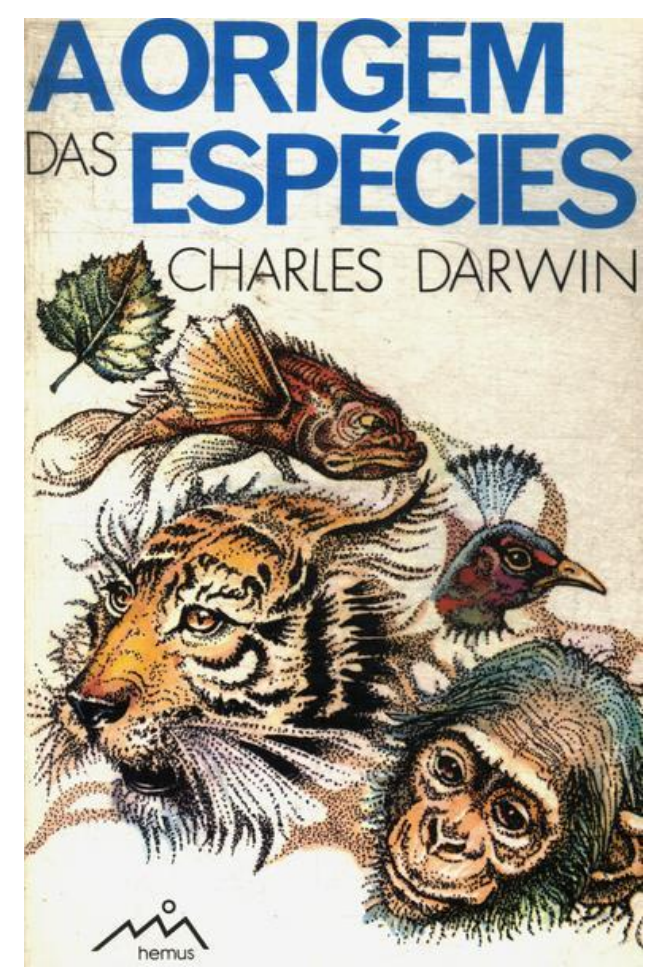

Figura 10 - Pretensa tradução de Eduardo Fonseca Fonte: Darwin (1981)

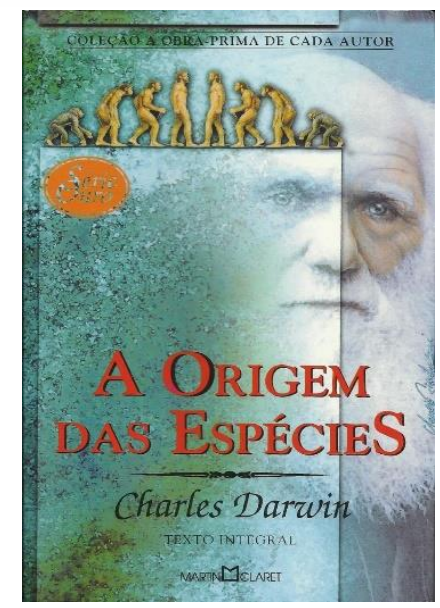

Figura 11 - Pretensa tradução de John Green Fonte: Darwin (2014b) 


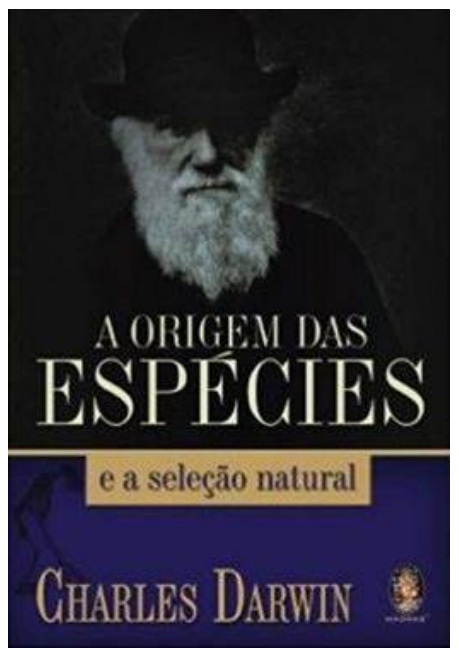

Figura 12 - Pretensa tradução de Caroline Furukawa Fonte: Darwin (2004)

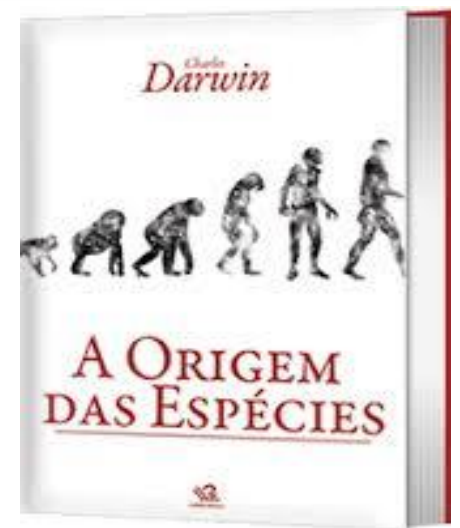

Figura 13 - Capa da tradução (problemática) de André Mesquita Fonte: Darwin (2009c) 


\section{O caso das lagostas voadoras de André Campos Mesquita e da Editora Es- cala}

Como já foi dito antes, apresento aqui alguns resultados de uma pesquisa iniciada há cinco anos no GP de Science Studies da UEM, que teve como uma de duas atividades a leitura e discussão da Origem. ${ }^{5}$ Logo no primeiro encontro nos deparamos com o problema da tradução: que edição iríamos usar? Apesar das dificuldades facilmente previstas de cada um usar uma edição diferente numa leitura coletiva, inclusive as edições originais, sugeri exatamente isso. Assim poderíamos agregar as diferenças tradutórias nas nossas análises, não imaginando que iria me surpreender tanto ao longo do processo.

A surpresa foi virando perplexidade conforme a leitura avançava. A edição que escolhi, traduzida por André Campos Mesquita e publicada pela Editora Escala (DARWIN, 2009c), foi adquirida num sebo da cidade de Maringá por 25 reais, ou seja, qualquer um poderia tê-lo comprado. Além disso, apesar de não se encontrar mais em livrarias, essa edição é facilmente encontrada em bibliotecas e sebos físicos ou virtuais. É uma edição com extensas margens, o que me permitiria fazer anotações. Evidentemente não imaginava que o número de anotações sobre os problemas de tradução iria suplantar em muito o número de anotações de compreensão do texto, que foi extenso.

Antes do início da leitura propriamente dita, fiz uma pesquisa rápida para saber quem era o tradutor da edição que eu havia adquirido e se havia alguma informação sobre as traduções da Origem em português. Alegrei-me ao ver que a colega pesquisadora de tradução, Denise Bottmann, já havia dado início em seu blog (BOTTMANN, 2009) a uma discussão sobre as traduções da Origem em português, denunciando os plágios de tradução que se encontram na tabela anterior. Encontrei ainda duas matérias, no Observatório da Imprensa, escritas por Felipe Costa $(2011 ; 2014)$, preocupado com a leitura de Darwin em português. Ele também faz referência às denúncias de Denise Bottmann. Foi no blog dela também que vi um comentário do tradutor da

${ }^{5}$ Essa atividade, como todas as outras, foi registrada detalhadamente no blog do grupo (Machado, 201318). 
edição que eu havia comprado, dizendo que a sua tradução foi publicada pela editora sem a sua autorização. Mau sinal, mas uma informação relevante. Voltei-me para o livro e fiz aquela leitura geral de sumário, orelhas, introdução. A princípio, nenhum problema além dos aceitáveis erros menores, fruto de uma publicação não revisada: "O livro que abalou ao [sic] mundo" (DARWIN, 2009c, p. 10); “As reações à Origem das espécies foi imediata [sic]" (ibid., p. 11); referência ao "jornal" da Linnean Society, que ficaria melhor traduzido como "periódico" ou "revista científica" (p. 14).

Eu estava otimista, acho que todos os tradutores e/ou estudiosos da tradução somos um pouco. Sobre o tradutor, descobri que era um colega professor de metodologia de pesquisa, autor de livro sobre Darwin e doutorando em Linguística na Unicamp, com uma pesquisa sobre o léxico científico de Darwin e o vocabulário do darwinismo social. Continuei otimista, eu estava nas mãos de um tradutor especialista que sabia o que estava fazendo. Ledo engano.

Depois de quatro capítulos que me incomodaram em certos trechos com vários tipos de problemas que foram se acumulando, meu otimismo acabou: "tendilhão" [finch'] (p. 30); "reduzido a prática" (p. 38); "que em certo número de casos não podamos reconhecer" (p. 41); "dez e sete plumas" (p. 42); "sobrevivência dos mais adequados/fortes" [fittest"]; (p. 64, 78); "pudemos ter tomado o caso" (p. 88); "Assa Gray" [Asa Gray8] (p. 104); "o quadro é minúscula" (p. 108); "podemos explicar-nos este fato" (p. 110); “substâncias indesejáveis" [dissimilar substances] (p. 115).

Até então eu atribuía esses problemas a escolhas tradutórias infelizes, pressa, falta de revisão, ou à minha dificuldade de entender as ideias gerais

\footnotetext{
${ }^{6}$ Tentilhão (finch), com “ $\mathrm{t}$ ”, talvez seja a espécie de pássaros mais famosa da obra de Darwin (apesar de ter sido economicamente mencionada por ele), tendo em vista as várias representações de seus bicos em diversos livros de e sobre Darwin. Um exemplo se encontra na capa da tradução portuguesa da Origem, feita por Ana Afonso (2009a). Darwin catalogou essa espécie em Galápagos, durante a sua viagem no Beagle.

${ }^{7}$ Um dos termos mais importantes da obra de Darwin, normalmente traduzido - e consagrado pela comunidade científica lusófona - como "apto". A tradução problemática desse termo está diretamente relacionada ao mal-entendido já mencionado sobre a noção de progresso (melhoria, perfeição, superioridade) na obra de Darwin.

8 Asa Gray (1810-1888) foi um botânico americano, professor de História Natural em Harvard e correspondente de Darwin.
} 
de Darwin, mas no quinto capítulo as coisas começaram a ficar claras para mim. O tradutor usou uma tradução espanhola como base. Não sei se podemos chamar propriamente de plágio, isto seria um bom objeto de estudo para pesquisadores como a Denise Bottmann, mas os castelhanismos, as falsas semelhanças, as diferenças de gênero entre o português e o espanhol começaram a ficar gritantes a partir desse capítulo. "As sementes se disseminam por sua pequeñez" (p. 172); "abelha reina" (p. 182); "que he sustentado" (p. 193); “follaje" (p. 196); "plieguecillos" (p. 201); "pasajeramente, segundo pôde verse" (p. 203); "pequeñuelo" (p. 206); entre várias outras ocorrências.

E eis as lagostas voadoras, "os grandes vôos de lagostas" [locusts] (p. 346), erro que ainda se repete na página seguinte: "uma nuvem de lagosta" (p. 347). Apesar da semelhança com o termo "lagosta" em português, locust significa gafanhoto, e ele, sim, voa. Além disso, nesse ecossistema produzido por André Mesquita, os "crocodilos xingam" [fight] (p. 84) e uma lagarta pode ficar "muito grávida" [embarassed] (p. 222). Tudo isso, provavelmente, graças a "razões gerais e vadias" [vagues] (p. 197).

O caso da lagarta foi destrinchado por Bottmann (2009), que desconfiou que "grávida" viesse do espanhol "embarazada". Ou seja, a tradução feita pelo André Mesquita está correta, mas não foi do original inglês, e sim da tradução espanhola de Antonio Zulueta, feita em 1921. Foi Zulueta que errou ao traduzir "embarassed". Em entrevista que fiz com o tradutor (MESQUITA, 2017a), ele confirmou que “consultou" uma tradução espanhola.

Em alguns momentos, por conta da alternância da legibilidade, eu também suspeitei de que tenha sido usado algum tradutor automático ou (menos provável) uma equipe de tradutores não especialistas e descoordenados: "quando uma flor é fértilda pelo vento" (p. 179). Esse "fértilda", que aparece várias outras vezes, pode ter sido uma tentativa de corrigir o termo automaticamente.

Enfim, esses são alguns poucos exemplos dos graves problemas dessa tradução. Evidentemente, não abandonei mais o original, que seguia ao meu lado sempre que me aventurava pelo livro traduzido, o que no mínimo duplicou o meu trabalho de compreensão do texto. Finalizada essa atividade dura - porém produtiva - de quase três anos, que rendeu belos frutos 
em seminários, iniciações científicas e trabalhos de conclusão de curso, achei que era minha obrigação compartilhar essa experiência com meus colegas pesquisadores de tradução, os leitores interessados em tradução científica e, sobretudo, os incautos leitores de Darwin em língua portuguesa.

Além de apresentar publicamente esse caso no Congresso da Abrapt em 2016 (MACHADO, 2016), fiz um pós-doc em 2017 para terminar o levantamento das traduções, fazer entrevistas e estudar a recepção luso-brasileira do darwinismo. Foi nesse contexto que entrevistei André Mesquita. Ele me disse que já defendeu sua tese de Doutorado em Linguística pela Unicamp, Evolução em Darwin: uma trajetória de sentidos, que fez a tradução da Origem em três meses e que considera que foi bem pago. Ele reconhece os problemas na tradução e afirma que isso é um fardo para ele, mas justifica o ocorrido dizendo que a editora publicou uma versão que ele enviara por e-mail para o setor financeiro fazer a contagem de laudas (MESQUITA, 2017a).

É evidente que a editora errou, foi incompetente, irresponsável, sequer fez uma revisão no livro antes de publicar, mas por que um tradutor enviaria arquivos diferentes para o editor e para o setor financeiro? Por que o editor falaria para ele fazer isso? E pior, como nenhum dos envolvidos achou isso estranho? Não vou entrar nas questões éticas envolvidas - que considero graves -, mas esse texto, do jeito que foi publicado, não poderia ser entregue nem a uma mãe benevolente que ama incondicionalmente o seu filho. Depois dessa vergonha pública, diz ele que cortou relações com a editora, mas, a meu ver, agora é tarde demais, sobretudo se considerarmos que esse livro foi distribuído para 2.700 bibliotecas públicas (BOTTMANN, 2009) e que, em 2018, essa mesma editora, agora chamada Lafonte, relançou a tradução, aparentemente sem as lagostas voadoras (MESQUITA, 2018). Parece que agora eles conseguiram acertar o arquivo.

Apesar disso tudo, André Mesquita tornou-se um especialista em Darwin e na Origem, com tese de doutorado (2017b) e livro publicado (pela Lafonte) sobre o assunto (MESQUITA, 2011). Em apresentação feita num simpósio, Mesquita (2010) resume assim o seu trabalho:

Em 2005, publiquei uma tradução da sexta edição de A Origem das Espécies pela Editora Escala, que foi relançada em 2009 na ocasião do centenário 


\begin{abstract}
do autor. O texto base foi o da $6^{\text {a }}$. edição da John Murray publicado em 1876.

O objetivo da tradução era incorporar notas explicativas e minibiografias dos colaboradores de Darwin e com explicação sobre algumas opções na tradução das espécies mencionadas. Lamentavelmente, por pressões de prazos da Editora Escala o texto que acabou sendo publicado era um rascunho da tradução ainda sem revisão, por isso não tem uma boa fluidez e há uma série de equívocos sérios que precisam ser corrigidos.
\end{abstract}

Além dessa benevolente autoavaliação, nesse texto ele tratou de problemas terminológicos da tradução da Origem, comparou traduções, fez análises críticas e ainda registrou a história de plágios e traduções espúrias desse livro no Brasil. Infelizmente, agora ele faz parte dela.

\title{
Considerações finais
}

Antes de finalizar, é importante registrar que, quando iniciei essa pesquisa, não tinha a intenção de fazer crítica de tradução ou de emitir juízo de valor sobre a tradução estudada, mas, com o desenrolar dos fatos aqui descritos, não havia outra saída, e entendi que era minha responsabilidade divulgar esse caso da história das traduções da Origem em língua portuguesa.

Em resumo, algumas traduções da Origem que temos disponíveis hoje em português são verdadeiros atentados ao vernáculo, ao direito do tradutor (casos de plágio de tradução) e à formação científica, o que pode afastar o neófito da bibliografia primária para sempre, afetando não só a formação científica, mas também a divulgação e a compreensão pública da ciência. Num mundo em que, ao contrário, precisamos nos aproximar da ciência, saber o que os cientistas estão fazendo, "seguir cientistas e engenheiros sociedade afora" (LATOUR, 2011), e conhecer minimamente os seus processos para entrar na discussão e tomar decisões que podem, no limite, afetar o destino da humanidade, o problema da tradução científica torna-se urgente. É nesse sentido que venho defendendo há anos que a parceria entre os Estudos da Tradução e os Science Studies pode ser muito produtiva. Com essa pesquisa ficou ainda mais claro que essa parceria enriquece a história da tradução científica e os estudos sobre a sua recepção. 
Em relação à Origem especificamente, há diversos problemas na sua recepção, alguns já brevemente mencionados aqui. É uma lástima que justamente a tradução tenha agregado mais um obstáculo à sua leitura - como a Editora Escala e André Mesquita fizeram -, afinal, a tradução já é uma atividade mal afamada, isso quando não passa totalmente invisível. Sobre o livro aqui denunciado, que é um caso lamentável para a história da tradução científica no Brasil, a alternativa a queimar todos os exemplares dessa perigosa publicação (imagem horrível de livros em chamas, que tanto trauma já nos causou) é a reflexão sobre a atividade tradutória a partir das belas palavras de George Szirtes traduzidas por Paulo Britto:

\footnotetext{
O tradutor esbarra em si próprio saindo do quarto da amante. Fidelidade, pois sim, ele pensa. [...] O guarda-roupa do tradutor estava cheio de camisas alheias. Pelo menos elas davam nele. O tradutor estava parado em frente à janela, fingindo que era transparente. Mas se tudo é potencialmente tudo o mais, queixou-se o tradutor, o que é que eu estou fazendo aqui? [...] O tradutor estava admirando seus poetas mortos. Não que eu esteja vivo, ele comentou, mas pelo menos eu me mexo sem parar. (SZIRTES, 2014, meus grifos).
}

No caso em questão, o tradutor não se mexia...

\section{Referências}

BELLINI, Luzia Marta. O conceito de evolução nos livros didáticos: uma avaliação metodológica. Revista Estudos em Avaliação Educacional, Fundação Carlos Chagas, São Paulo, no. 33, 2006.

BIZZO, Nelio. Ensino de evolução e história do darwinismo. Tese de Doutorado (Educação). USP, 1991.

BOTTMANN, Denise. Todas as postagens sobre a Origem das espécies desde 2009. Blog não gosto de plágio. Disponível em: < http://naogostodeplagio.blogspot.com/search/label/darwin>. Acesso em outubro 2018.

COSTA, Felipe. Lendo Darwin em português. Observatório da Imprensa, edição 802, 10/06/2014. Disponível em: <http://observatoriodaimprensa.com.br/armazem-literario/_ed802_lendo_darwin_em_portugues/>. Acesso em outubro 2018. 
Nem sempre é culpa da mídia. Observatório da Imprensa, edição 631, 01/03/2011. Disponível em: <http://observatoriodaimprensa.com.br/jornal-de-debates/nem-sempre-e-culpa-da-midia/>. Acesso em outubro 2018. DARWIN, Charles. A origem das espécies. Organização, apresentação e tradução de Pedro Paulo Pimenta. Ilustrações de Alex Cerveny. São Paulo: Ubu Editora, 2018a.

. Sobre a origem das espécies. Tradução de Daniel Miranda. Prefácio, revisão técnica e notas de Nelio Bizzo. São Paulo: Edipro, 2018b.

A origem das espécies, 6a. ed. Tradução de Carlos e Anna Duarte. Prefácio de Nelio Bizzo. São Paulo: Martin Claret, 2014a.

A origem das espécies. Tradução (pretensa) de John Green. São Paulo: Editora Martin Claret, 2014b.

A origem das espécies, $1^{a}$. ed. Tradução de Vítor Guerreiro. Prefácio de Michael Ruse. Lisboa: Verbo-Babel, 2011.

. A origem das espécies e a seleção natural. $6^{\mathrm{a}}$. ed. Tradução de Soraya Freitas. São Paulo: Madras, 2011.

A origem das espécies, 6a. ed. Tradução de Ana Afonso. Leça da Palmeira, Portugal: Editora Planeta Vivo, 2009a.

A origem das espécies, 6a . ed. Tradução de Joaquim Dá Mesquita Paúl. Revisão de João Arrepia. Porto: Lello Editores, 2009b.

A origem das espécies, 6a. ed. Tradução de André Campos Mesquita. SP: Editora Escala, 2009c.

A origem das espécies, 1a. ed. Tradução de Dora Batista. Mem Martins, Portugal: Publicações Europa-América, 2005.

A origem das espécies e a seleção natural. Tradução (pretensa) de Caroline Furukawa. São Paulo: Madras, 2004.

Origem das espécies, 1a․ ed. Tradução de Eugênio Amado. BH: Editora Itatiaia, 2002.

A origem das espécies. Tradução (pretensa) de Eduardo Fonseca. São Paulo: Hemus, 1981.

A origem das espécies, 6a . ed. Tradução de Joaquim Dá Mesquita Paúl. Porto: Livraria Chardron, de Lello \& Irmão, s/data [1913]. 
The origin of species by means of natural selection. 6th ed. Londres: John Murray ed., 1876. Disponível em: <http://darwin-online.org.uk/). Acesso em outubro 2018.

. On the origin of species by means of natural selection. 1a. ed. Londres: John Murray ed., 1859. Disponível em: <http://darwin-online.org.uk/). Acesso em outubro 2018.

. Carta 729 para Joseph Hooker, 11 de janeiro de 1844. Disponível em $<$ http://www.darwinproject.ac.uk/entry-729>. Acesso em outubro 2018.

DARWIN CORRESPONDENCE PROJECT. Cambridge University Library. Disponível em: <http://www.darwinproject.ac.uk/>. Acesso em outubro 2018.

DARWIN ONLINE. John van Wyhe (Ed.). The complete work of Charles Darwin online. 2002-. Disponível em: <http://darwin-online.org.uk). Acesso em outubro 2018.

DOMINGUES, H. M. B.; SÁ, M. R.; GLICK, T. (Orgs.) A recepção do darwinismo no Brasil. Rio de Janeiro: Editora Fiocruz, 2003.

FERREIRA, V.; MACHADO, C. O darwinismo na UEM: o caso do vestibular de 2008. In: BELLINI, L. M. (Org.). Dossiê: Complexidade, Ciências da Vida e Educação. Koan: Revista de Educação e Complexidade, edição 4, jan 2016 [2018], p. 88-105.

FONSECA, Pedro Ricardo Gouveia da. Darwin em Portugal (1910-1974): o darwinismo e a evolução na produção científica de botânicos portugueses. Tese de Doutorado (Altos Estudos em História). Universidade de Coimbra, 2015.

FREEMAN, Richard Broke. The works of Charles Darwin: an annotated bibliographical handlist. 2nd. ed. Dawson: Folkstone, 1977. Disponível em: $<$ http://darwin-

online.org.uk/content/frameset?pageseq $=1 \&$ itemID $=\mathrm{A} 1 \&$ viewtype $=\quad$ text $>$. Acesso em outubro 2018.

LATOUR, Bruno. Ciência em ação: como seguir cientistas e engenheiros sociedade afora. Tradução de Ivone Benedetti. São Paulo: Editora Unesp, 2011. MACHADO, Cristina de Amorim (Ed.). Todas as postagens sobre a Leitura de Darwin desde 2013. Blog do GP de Science Studies da UEM. Disponível 
em: $\quad<$ https://gpsciencestudiesuem.wordpress.com/category/leituras-darwin/>. Acesso em outubro 2018.

. Reflexões sobre a tradução e a circulação do conhecimento científico: o caso da Origem das espécies, de Charles Darwin. In: SILVA, Igor et al. (Orgs.). Entrad: Caderno de Resumos. Uberlândia: UFU, 2016, p. 164-165. MESQUITA, André Campos. Re: Confirmação de entrevista na quinta, 30 de novembro, às $\mathbf{1 8 h}$. [mensagem pessoal]. Mensagem recebida por <cristina_machado@yahoo.com> em 3 de junho de 2018.

Conversa sobre as traduções da Origem das espécies [nov. 2017]. Entrevistadora: Cristina de Amorim Machado. São Paulo, 2017a. Áudio disponível em: <http://gpsciencestudiesuem.wordpress.com/>. Acesso em outubro 2018.

Evolução em Darwin: uma trajetória de sentidos. Tese de Doutorado (Linguística). Unicamp, 2017b.

Darwin: o naturalista da evolução das espécies. São Paulo: Editora Lafonte, 2011.

Análise das traduções para o português de $A$ origem das espécies de Charles Darwin. II Simpósio de Filologia e Cultura Latino-Americana [texto inédito cedido pelo autor], 2010.

NAVARRO, Pedro de Lima. Frequência e contexto de citação dos colaboradores de Charles Darwin na Origem das espécies. Trabalho de Conclusão de Curso (Ciências Biológicas). UEM, 2018.

OLIVEIRA, Graciela da Silva. Estudantes e a evolução biológica: conhecimento e aceitação no Brasil e Itália. Tese de Doutorado (Educação). USP, 2015.

PEREIRA, Ana Leonor. Darwin em Portugal: filosofia, história, engenharia social (1865-1914). Coimbra: Editora Almedina, 2001.

PETRUCCI, I.; BELLINI, L. M. A recepção de Darwin entre alunos do curso de ciências biológicas da Universidade Estadual de Maringá. In: BELLINI, L. M. (Org.). Dossiê: Complexidade, Ciências da Vida e Educação. Koan: Revista de Educação e Complexidade, edição 4, jan 2016 [2018], p. 106-126. 
SZIRTES, George. Posfácio: a morte do tradutor. Tradução de Paulo Henriques Britto. Revista Piauí, edição 89, fev/2014. Disponível em: http:// piaui.folha.uol.com.br/materia/posfacio-a-morte-do-tradutor/. Acesso em outubro 2018.

VENUTI, Lawrence. Escândalos da tradução: por uma ética da diferença. Tradução de Laureano Pelegrin, Lucinéia Marcelino Villela, Marileide Dias Esqueda e Valéria Biondo. Bauru: EDUSC, 2002.

\title{
Resumo
}

O objetivo deste trabalho é apresentar uma breve história das traduções lusobrasileiras da Origem das espécies, obra na qual Charles Darwin (1859) formulou a teoria da evolução por seleção natural. A primeira tradução integral da Origem em português foi publicada no Porto em 1913. Além de contribuir para uma história da tradução científica em língua portuguesa, esta pesquisa é relevante para os estudos da recepção do darwinismo no Brasil e em Portugal, tendo em vista que algumas chaves de leitura dessa obra só se revelam com um olhar mais cuidadoso para a tradução.

Palavras-chave: Tradução científica; Darwin; Origem das espécies; História da tradução; Recepção do darwinismo.

\begin{abstract}
This paper intends to present a brief history of the Portuguese and Brazilian translations of the Origin of Species, book in which Charles Darwin (1859) establish the theory of evolution by means of natural selection. The first full Portuguese translation of the Origin was published in Porto in 1913. Since some crucial points in its reading only appear if we pay attention to translation, this research contributes to the history of the scientific translation and to the studies of the reception of Darwinism in Brazil and Portugal.
\end{abstract}

Keywords: Scientific translation; Darwin; Origin of Species; Reception of Darwinism; History of translation. 